\title{
Catabolite repression by glucose 6-phosphate, gluconate and lactose in Escherichia coli
}

Boris M. Hogema, ${ }^{1}$ Jos C. Arents, ${ }^{1}$ Toshifumi Inada, ${ }^{2}$ Hiroji Aiba, ${ }^{2}$ Karel van Dam ${ }^{1}$ and Pieter W. Postma ${ }^{1 *}$ ${ }^{1}$ E. C. Slater Institute, BioCentrum, University of Amsterdam, Plantage Muidergracht 12, 1018 TV Amsterdam, The Netherlands.

${ }^{2}$ Department of Molecular Biology, School of Science, Nagoya University, Chikusa, Nagoya 464-01, Japan.

\section{Summary}

While catabolite repression by glucose has been studied extensively and is understood in large detail in Enterobacteriaceae, catabolite repression by carbohydrates that are not transported by the phosphotransferase system (PTS) has always remained an enigma. Examples of non-PTS carbohydrates that cause catabolite repression in Escherichia coli are gluconate, lactose and glucose 6-phosphate. In this article it is shown that enzyme IIA ${ }^{\text {Glc }}$ of the PTS is not involved in catabolite repression by these carbon sources. Carbon sources that caused strong catabolite repression of $\beta$-galactosidase lowered the concentration of both CAMP and the CAMP receptor protein (CRP). A strong correlation was found between the amounts of CAMP and CRP and the strength of the repression. The levels of CAMP and CRP were modulated in various ways. Neither overproduction of CRP nor an increased cAMP concentration could completely relieve the repression by glucose 6-phosphate, lactose and gluconate. Simultaneously increasing the CAMP and the CRP levels was lethal for the cells. In a mutant expressing a constant amount of CAMP-independent CRP* protein, catabolite repression was absent. The same was found in a mutant in which lac transcription is independent of CAMP/CRP. These results, combined with the fact that both the CAMP and the CRP levels are lowered by glucose 6-phosphate, lactose and gluconate, lead to the conclusion that the decreased CAMP and CRP levels are the cause of catabolite repression by these nonPTS carbon sources.

\section{Introduction}

In microorganisms, certain carbon sources are preferred

Received 31 January, 1997; revised 20 March, 1997; accepted 2 April, 1997.*For correspondence. E-mail postma@chem.uva.nl; Tel. (20) 5255112; Fax (20) 5255124. to others. This phenomenon was studied extensively by J. Monod in the 1940s, who observed that Escherichia coli, when it is offered, for example, both lactose and glucose, preferentially uses glucose and starts to metabolize lactose only when the glucose is exhausted (Monod, 1942). Monod referred to this as 'diauxic growth', and found that many pairs of carbohydrates exhibit this behaviour. Later, the more general term 'catabolite repression' was introduced (Magasanik, 1961). Subsequently, this term was restricted to describe only the permanent and not the transient repression of genes (Magasanik, 1970). More recently, the term catabolite repression became used to describe the general phenomenon whereby the presence of certain compounds in the medium (e.g. carbon sources or nitrogen sources) can repress the expression of certain genes or operons (see Wanner et al., 1978; Postma and Lengeler, 1985; Saier et al., 1996). Most research has focussed on catabolite repression by carbohydrates, which can be defined as the inhibitory effect of a carbon source in the growth medium on the gene expression and/or the activity of proteins involved in catabolism of other carbon sources. 'Carbon catabolite repression' and the 'glucose effect' are still sometimes used as synonyms, which is confusing because carbon sources other than glucose can also cause catabolite repression. We will use the term 'glucose repression' only to indicate catabolite repression elicited by glucose. Catabolite repression has been observed in many different prokaryotes, but research has mainly focussed on repression in $E$. coli, a few other enteric bacteria, and some other organisms such as Bacillus subtilis.

Glucose-mediated catabolite repression in E. coli is now quite well understood (recently reviewed by Postma et al., 1993; Kolb et al., 1993; Saier et al., 1996). The current model proposes that glucose repression is mediated by dephosphorylation of enzyme IIA ${ }^{\text {Glc }}$, which is one of the enzymes involved in glucose transport. Glucose and many other carbohydrates are transported by the phosphoenolpyruvate:carbohydrate phosphotransferase system (PTS), a complex carbohydrate uptake system which, via several enzymes, sequentially transfers a phosphoryl group originating from phosphoenolpyruvate to a carbohydrate molecule, which is then transported concomitantly. All PTS proteins become phosphorylated and dephosphorylated during this process. When a PTS carbohydrate is transported, the phosphorylation state of the PTS enzymes changes. The phosphorylation state of enzyme $\| A^{\text {Glc }}$ 
regulates catabolite repression by PTS substrates both at the post-transcriptional level and at the transcriptional level. When enzyme $I I A^{\text {Glc }}$ is in the dephosphorylated state, i.e. when carbohydrate is transported, it binds to, and thereby inactivates, the transport systems of a number of non-PTS carbon sources (reviewed by Postma et al., 1993). Consequently, induction of the genes encoding metabolic pathways necessary for the metabolism of these carbon sources is prevented. For this reason, this process is called 'inducer exclusion'. The other mechanism by which dephosphorylation of enzyme IIA ${ }^{\text {Glc }}$ causes repression is by decreasing the concentration of CAMP in cells grown on glucose or other PTS carbohydrates. It has been proposed that phosphorylated IIA ${ }^{\text {Glc }}$ stimulates the cAMP biosynthetic enzyme, adenylate cyclase (reviewed by Postma et al., 1993; Kolb et al., 1993; Botsford and Harman, 1992). Cyclic AMP can bind to the cAMP-receptor protein (CRP) to form the cAMP-CRP complex, which is a regulatory factor for the transcription of at least 45 genes, including the lac operon (Botsford and Harman, 1992).

Regulation of the concentration of the cAMP-CRP complex has for a long time been thought to be mediated only by changes in the CAMP concentration. More recently, it was discovered that the concentration of CRP is also lowered in cells grown on glucose compared to the level in cells grown on succinate, and that this is an additional important factor contributing to catabolite repression by glucose (Ishizuka et al., 1993). The mechanism for the glucose-mediated decrease in CRP is not yet fully understood, but has been shown to be a consequence of the complex regulation of the crp gene, which is both positively and negatively regulated by the CAMP-CRP complex, depending on the concentration of the complex (Ishizuka et al., 1994; Hanamura and Aiba, 1992).

Although catabolite repression by glucose and other PTS carbohydrates is quite well understood, it should be realized that our knowledge of catabolite repression is still far from complete, even in E. coli. A number of studies have indicated that, in $E$. coli, cAMP/CRP-independent mechanisms may be involved in catabolite repression (reviewed by Magasanik and Neidhardt, 1987; Ullmann and Danchin, 1983; Saier et al., 1996). Furthermore, it has been known for a long time that, in E. coli, carbon sources that are not transported by the PTS, and which therefore are not expected to change the phosphorylation state of enzyme IIA ${ }^{\text {Glc }}$, can also cause very strong catabolite repression, which is often even stronger than that by glucose. Examples are glucose 6-phosphate (Perlman et al., 1969) and gluconate (Okinaka and Dobrogosz, 1966). Surprisingly, the expression of the lac operon, induced with IPTG, is higher in cells grown on glycerol or succinate than in cells grown on lactose; therefore, lactose also represses the genes necessary for its own metabolism
(Jacob and Monod, 1961; Ishizuka et al., 1993; Inada et al., 1996).

Repression by glucose 6-phosphate in enteric bacteria has been studied to some extent. It has been found that glucose 6-phosphate still causes catabolite repression in a mutant lacking enzyme I of the PTS (Yang et al., 1979), which suggests that the PTS is not involved in the repression. The role of cAMP in glucose 6-phosphate repression is not clear. It has been shown that the lactose operon is not repressed by glucose 6-phosphate in the $E$. coli lacL8UV5 mutant (often called the lacUV5 mutant), in which lac expression is independent of CAMP and CRP levels (Silverstone et al., 1970). Although this result suggests that CAMP and/or CRP is involved in the repression, there is no agreement about the role of CAMP, because some authors showed that addition of cAMP to the culture medium largely overcomes catabolite repression by glucose 6-phosphate (Perlman et al., 1969; Yang et al., 1979), while others claimed the opposite (Goldenbaum and Dobrogosz, 1968).

Repression by gluconate and lactose has hardly been studied. It has been shown that gluconate causes strong catabolite repression of $\beta$-galactosidase synthesis (Okinaka and Dobrogosz, 1966), and that the cAMP level in gluconate-grown cells is low (Epstein et al., 1975). Growth on lactose also leads to low cAMP levels in the cell (Inada et al., 1996).

In this report, we analysed catabolite repression by glucose 6-phosphate, lactose and gluconate in different $E$. coli mutants. We modulated CAMP and CRP levels, and we measured CAMP and CRP levels in cells grown on different carbon sources. We have also shown that the nonPTS carbon sources cause a decrease in the CAMP and CRP levels. Neither the decrease in cAMP nor the decrease in CRP individually is sufficient to explain catabolite repression, but the combined decrease of CAMP and CRP levels can explain catabolite repression by these compounds.

\section{Results}

The PTS is not involved in catabolite repression by glucose 6-phosphate, lactose and gluconate

In order to investigate the possible role of the PTS in repression by glucose 6-phosphate, lactose and gluconate, we measured repression of $\beta$-galactosidase in a wild-type $E$. coli strain and an isogenic $\mathrm{Crr}^{-}$mutant (which lacks enzyme $\| A^{\text {Glc }}$, the global regulator in glucose-mediated catabolite repression). The lac $Z$ gene (encoding $\beta$-galactosidase) was induced with $0.4 \mathrm{mM}$ IPTG. Since IPTG can enter the cell even in the absence of the lactose transporter (encoded by lacY), inducer exclusion does not play a role when IPTG is used as inducer.

Glucose 6-phosphate, lactose and gluconate caused 
Table 1. Catabolite repression of $\beta$-galactosidase in different mutants.

\begin{tabular}{|c|c|c|c|c|c|}
\hline Strain & Lactate & Lactate + glucose 6-phosphate & Lactate + gluconate & Lactate + glucose & Lactate + lactose \\
\hline MG1655 (wild type) & 12800 & 1260 & 4920 & 3350 & 2900 \\
\hline PPA484 (crr-1) & 8000 & 460 & 1930 & 4880 & 1060 \\
\hline PPA549 (lacL8UV5) & 8280 & 6980 & 7240 & 7080 & 6710 \\
\hline ATCC8739 (cpdA) & 12620 & 1980 & 5580 & 4730 & 2720 \\
\hline MG1655 + $2.5 \mathrm{mM}$ cAMP & 14310 & 2160 & 8020 & 10130 & 4450 \\
\hline MG1655 + pFCRP7 & 15390 & 1860 & 7670 & 5540 & 4450 \\
\hline IT1106 (crp*) & 6810 & 2000 & 3780 & 3780 & 2780 \\
\hline PPA530 (cya crp) + pHA7G141D & 3060 & $2100^{a}$ & 3240 & 2730 & 2650 \\
\hline PPA523 (del lacZY) +plT296 & 1600 & 1660 & 1500 & 1210 & $N D^{b}$ \\
\hline
\end{tabular}

Beta-galactosidase activities were measured as specified in the Experimental procedures, with IPTG as inducer of the lacZ gene. Activities are expressed in Miller units. At least three samples were taken and values are the average value of at least two independent experiments. The SEM was less than $10 \%$.

a. The activity became lower at higher cell density (see the text).

b. ND, not determined.

approximately 10 -fold, fourfold and threefold repression, respectively, in a wild-type strain. Strong repression by lactose, gluconate and glucose 6-phosphate was still observed in the $\mathrm{Crr}^{-}$mutant (Table 1): in fact, the repression is relatively stronger in the $\mathrm{Crr}^{-}$mutant. Thus, we conclude that enzyme IIA ${ }^{\text {Glc }}$ is not the mediator of catabolite repression by these carbon sources. Only in the case of glucose was repression in the $\mathrm{Crr}^{-}$mutant less strong than in the wild-type strain, showing, as expected, that enzyme IIA Glc is involved in glucose repression. The residual repression in the $\mathrm{Crr}^{-}$mutant may be caused by a glucose-mediated reduction in the CRP level, or even by an enzyme $\| A^{\text {Glc }}$-independent decrease in the cAMP concentration, because it has been shown that the total cAMP production is still downregulated by glucose in a $\mathrm{Crr}^{-}$ mutant (Dumay et al., 1996).

\section{Re-examination of the role of cAMP in catabolite} repression by glucose 6-phosphate, lactose and gluconate

The possibility that a decrease in the cAMP concentration is the mediator of catabolite repression by glucose 6-phosphate, lactose and gluconate has been investigated to some extent. The most important observation has been that there is no repression of $\beta$-galactosidase synthesis by glucose 6-phosphate in the lacL8UV5 mutant (Silverstone et al., 1970).

We have repeated the $\beta$-galactosidase measurements in a lacL8UV5 mutant (PPA549) that is isogenic with our wild-type strain MG1655. All carbon sources tested caused only very weak repression (Table 1). The absence of repression in the lacL8UV5 mutant strongly suggests that the CAMP-CRP complex is involved in regulation of catabolite repression by these carbon sources.

Another indication for the involvement of CAMP in repression by glucose 6 -phosphate, lactose and gluconate is the observation reported by different groups that the
cAMP level in cells grown on these carbon sources is low. In fact, the cAMP level in glucose 6-phosphategrown cells is even lower than that in glucose-grown cells (Epstein et al., 1975; Joseph et al., 1982). However, the reported cAMP levels differ significantly in these studies and it is not clear whether this is because of a difference between the procedures used to extract and measure cAMP or because of the use of different strains. To resolve this question, we determined the CAMP levels in our wildtype strain. Filtration, centrifugation and the fixation of the intracellular cAMP in cold $\left(-40^{\circ} \mathrm{C}\right) 50 \%$ methanol were compared as methods for harvesting the cells. Filtration gave the most reliable results. The data in Table 2 and Fig. 1 show that the cAMP levels are the lowest in cells grown on carbon sources that cause stronger repression. The cAMP levels we have measured are between 0.4 and $3.1 \mu \mathrm{M}$, which is comparable to the values reported by Epstein et al. (1975), but much lower than those reported by Joseph et al. (1982). In both reports, the cAMP level in glucose 6-phosphate-grown cells was lower than that in glucose-grown cells, which agrees with our finding. We have checked that the cAMP level is also decreased by glucose 6-phosphate in a $\mathrm{Crr}^{-}$mutant. Because the cAMP level in $\mathrm{Crr}^{-}$mutants is much lower than that in the wild-type strain, it was not possible to determine the

Table 2. cAMP and CRP levels in cells of strain MG1655 grown on different carbon sources.

\begin{tabular}{lll}
\hline Carbon source & $\operatorname{cAMP}(\mu \mathrm{M})$ & $\mathrm{CRP}(\mu \mathrm{M})$ \\
\hline Lactate & $3.30 \pm 0.10$ & $7.8 \pm 0.7$ \\
Lactate + glucose 6-phosphate & $0.40 \pm 0.02$ & $4.0 \pm 0.2$ \\
Lactate + gluconate & $1.04 \pm 0.04$ & $5.4 \pm 0.1$ \\
Lactate + glucose & $0.72 \pm 0.03$ & $4.9 \pm 0.4$ \\
Lactate + lactose & $0.70 \pm 0.05$ & $3.6 \pm 0.3$ \\
\hline
\end{tabular}

cAMP and CRP levels in the cell were measured as described in the Experimental procedures. Values for cAMP represent the average value $( \pm$ SEM) of at least three independent triplicate determinations. Values for CRP represent the average of five independent determinations ( \pm SEM). 


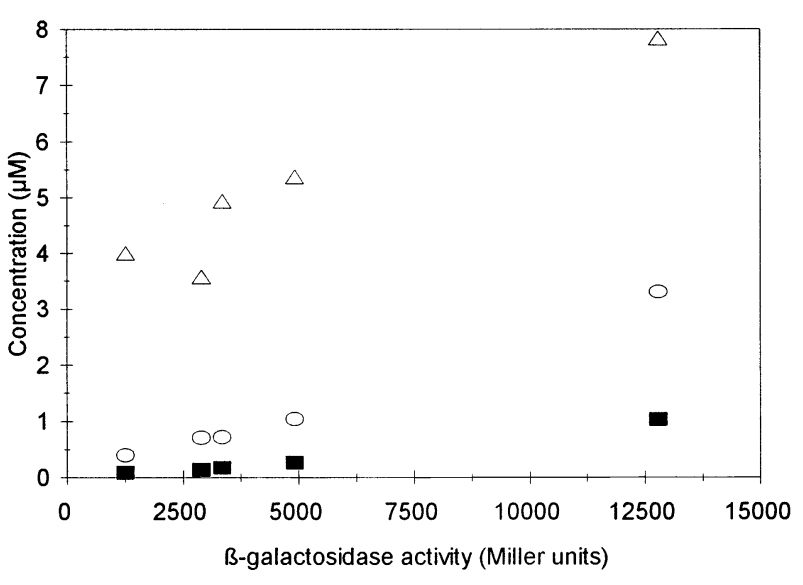

Fig. 1. The total concentration of $C A M P(O)$ and CRP dimer $(\triangle)$ (Table 2) and the calculated concentration of cAMP-CRP complex (ם) in MG1655 cells grown on different carbon sources, plotted against the corresponding $\beta$-galactosidase activities of the cells (Table 1). The calculated concentration of the complex is based on an equilibrium association constant of $6.7 \times 10^{4} \mathrm{M}^{-1}$ for cAMP binding to the CRP dimer (Cheng et al., 1993; Heyduk and Lee, 1989).

intracellular cAMP level accurately, but the extracellular level can be determined easily, because more than $95 \%$ of the CAMP in a culture of exponentially growing cells is found outside the cells (B. M. Hogema, unpublished; Epstein et al., 1975). The extracellular cAMP levels were $25 \mathrm{nM}$ and $8 \mathrm{nM}$ in mid-log-phase cultures $\left(\mathrm{OD}_{600}=0.5\right)$ of the $\mathrm{Crr}^{-}$mutant PPA484 grown on lactate and glucose 6-phosphate, respectively. Assuming a similar decrease in the intracellular cAMP concentration, this could explain the fact that there is still catabolite repression in the $\mathrm{Crr}^{-}$ mutant, and this provides further evidence that catabolite repression by glucose 6 -phosphate is not regulated by enzyme IIA ${ }^{\text {Glc }}$, but is nevertheless cAMP dependent.

If a lowered CAMP concentration is involved in catabolite repression by glucose 6-phosphate, lactose and gluconate, it can be expected that addition of cAMP to cells growing on these carbon sources relieves the repression to a large extent, as is the case with glucose-mediated repression (Ishizuka et al., 1993; Perlman et al., 1969). Repression by different carbon sources in our wild-type strain was measured in the presence of $2.5 \mathrm{mM}$ cAMP (Table 1). We confirmed that this concentration of CAMP strongly reduced glucose repression. Gluconate repression decreased slightly from $62 \%$ to $44 \%$ of the unrepressed activity (Table 1). In the case of glucose 6-phosphate and lactose, the effect of cAMP addition on the $\beta$-galactosidase activity was much smaller. Although cAMP addition increased the $\beta$-galactosidase activity from 1260 to 2160 Miller units in cells grown on glucose 6 -phosphate, the repression only decreased from $90 \%$ to $85 \%$ of the unrepressed activity. Lactose repression decreased from $77 \%$ to $68 \%$ by the addition of cAMP.
To exclude the possibility that breakdown of cAMP was stimulated by lactose, gluconate and glucose 6-phosphate, the extracellular CAMP levels in the cultures grown in the presence of $2.5 \mathrm{mM}$ cAMP were determined under conditions similar to those used for the induction studies. More than $90 \%$ of the added CAMP was recovered (data not shown), indicating that CAMP breakdown was not the reason that the repression was not relieved by adding $2.5 \mathrm{mM}$ cAMP. We also measured catabolite repression in a $c p d A$ mutant that lacks cAMP phosphodiesterase. Catabolite repression in this mutant was not significantly different from that in the wild-type strain (Table 1), again showing that cAMP breakdown is not involved in regulation of catabolite repression.

It is possible that the amount of cAMP that enters the cells or remains in the cells when exogenous CAMP is added is too low to overcome repression. Accurate measurement of the actual cAMP concentration in the cell is not possible when the extracellular concentration is very high. To be able to manipulate the cAMP level in the cells in such a way that the actual cAMP concentration can be monitored, we constructed an inducible expression vector ( $\mathrm{pBCP540)}$ containing the adenylate cyclase (cya) gene cloned behind the L-arabinose-inducible promoter of pBAD18. Repression of $\beta$-galactosidase was measured in wild-type cells transformed with pBCP540. The L-arabinose concentration was adjusted in such a way that the CAMP concentration was similar to or higher than that in wild-type cells (without plasmid) grown on lactate. In the case of glucose 6-phosphate, this was not possible, but the concentration was significantly increased. As before, repression by glucose and gluconate was partially relieved, while the effect of the higher intracellular CAMP concentration on glucose 6-phosphate-mediated repression was small (Table 3).

Table 3. Beta-galactosidase activity and cAMP levels in cells overproducing adenylate cyclase from the plasmid pBCP540.

\begin{tabular}{llll}
\hline Carbon source & $\begin{array}{l}\text { L-arabinose } \\
\text { concentration } \\
(\mu \mathrm{M})\end{array}$ & $\begin{array}{l}\text { Beta- } \\
\text { galactosidase } \\
\text { activity }\end{array}$ & $\begin{array}{l}\text { cAMP } \\
\text { concentration } \\
(\mu \mathrm{M})\end{array}$ \\
\hline $\begin{array}{l}\text { Lactate } \\
\text { Lactate }+\end{array}$ & 0 & 14400 & $7.5 \pm 2.0$ \\
$\begin{array}{l}\text { glucose 6- } \\
\text { phosphate }\end{array}$ & 75 & 1710 & $1.7 \pm 0.4$ \\
$\begin{array}{l}\text { Lactate + gluconate } \\
\text { Lactate + glucose }\end{array}$ & 10 & & \\
\hline
\end{tabular}

MG1655 transformed with pBCP540 was grown on the indicated carbon sources in the presence of the indicated concentration of arabinose. Beta-galactosidase and intracellular cAMP concentrations were determined as described in the Experimental procedures. Betagalactosidase activities are expressed in Miller units. To determine $\beta$-galactosidase activity, at least three samples were taken, and values are the average value of at least two independent experiments. The SEM was less than $10 \%$. 
The role of CAMP in catabolite repression by glucose 6-phosphate, lactose and gluconate was examined further by measuring repression in a Cya ${ }^{-}$Crp* mutant (containing a CRP* protein that is active in the absence of cAMP). In this mutant, repression by all substrates tested was still strong, albeit less strong than in the wild-type strain (Table 1). As this mutant does not contain cAMP, the mechanism of catabolite repression by these carbon sources cannot be dependent on CAMP under these conditions. In the case of glucose, it has been shown that repression is caused by a decrease in the amount of the CRP* protein (Tagami et al., 1995).

\section{Glucose 6-phosphate, lactose and gluconate lower the level of CRP}

The near-absence of repression in the lacL8UV5 mutant (Table 1) and the decrease in cAMP levels in cells grown on the different non-PTS carbon sources strongly suggest that a decrease in the concentration of the CAMP-CRP complex is the mediator of catabolite repression. The incomplete relief of repression by the addition of cAMP, and the occurrence of catabolite repression by glucose 6-phosphate, lactose and gluconate in IT1106, a Cya ${ }^{-}$ Crp* mutant (Table 1) on the other hand suggest that CAMP is not the sole mediator of catabolite repression by these compounds. We therefore determined, by means of immunoblotting, the amount of CRP in cells grown in minimal medium with different carbon sources. The result of a typical experiment is shown in Fig. 2, and the results are summarized in Table 2 . As has been shown previously by Ishizuka et al. (1993), glucose lowers the level of CRP compared to that in cells grown on a nonrepressing carbon source. The reduction in CRP level was somewhat smaller than the two- to threefold reduction reported previously, and may be caused by the use of a different non-repressing carbon source (lactate instead of succinate) or may reflect a difference between the

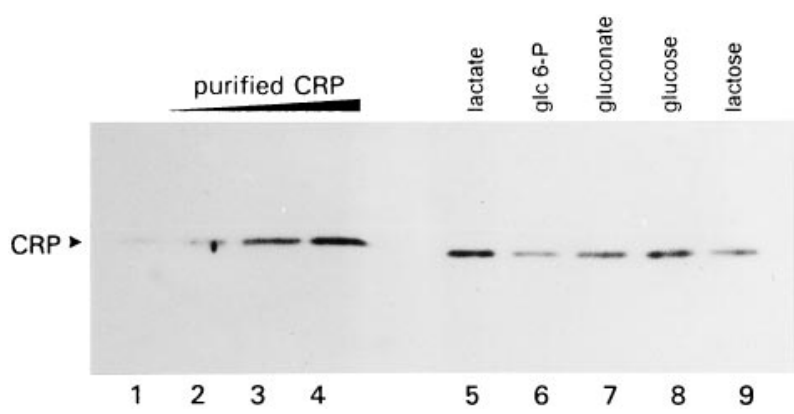

Fig. 2. Quantitative determination of CRP in wild-type cells by Western blotting. Cells were grown on different carbon sources and treated as described in the Experimental procedures. Lanes 1-4, Western blot of purified CRP protein $(0.65 \mathrm{ng}, 1.3 \mathrm{ng}, 2.7 \mathrm{ng}$ and $5.3 \mathrm{ng}$, respectively). Lanes $5-9$, Western blot of cell extracts from cells grown on the different carbon sources indicated. strains used. Gluconate lowered the CRP level to the same extent as glucose, while the CRP level in glucose 6 -phosphate-grown cells was $20 \%$ lower than that in glucose-grown cells. The CRP level in cells grown on lactose was slightly lower still.

The decrease in CRP level is not the only cause of catabolite repression by glucose 6-phosphate, lactose and gluconate

To check whether the reduced CRP levels in cells grown on glucose 6-phosphate, lactose or gluconate were the cause of catabolite repression by these compounds, catabolite repression by different carbon sources was measured in cells overproducing CRP from the pFCRP7 plasmid which contains the crp gene behind the constitutive bla promoter (Table 1). Gluconate repression was partly relieved, but, surprisingly, an increase in the CRP level did not relieve catabolite repression by lactose and glucose 6-phosphate. It was confirmed by immunoblotting that during growth on all carbon sources tested, the CRP level in the cells containing the crp plasmid was higher than that in wild-type cells during growth on lactate (data not shown). The strong repression in glucose 6-phosphate-grown cells containing the crp plasmid could therefore not be caused by reduced CRP levels, and the reduction in the CRP level can therefore not be the only cause of repression by glucose 6-phosphate and lactose.

\section{Catabolite repression by glucose 6-phosphate, lactose and gluconate is caused by the combination of a decrease in CAMP and CRP concentration}

While many lines of evidence suggest that catabolite repression by glucose 6 -phosphate, lactose and gluconate is CAMP/CRP dependent, neither addition of CAMP nor overproduction of CRP relieved the repression completely, especially in the case of lactose and glucose 6-phosphate. Because cya expression is reduced when CRP is overproduced (Aiba, 1985; Mori and Aiba, 1985) and adenylate cyclase activity is negatively regulated by CRP (reviewed by Botsford and Harman, 1992), overproduction of CRP could lead to lower cAMP levels, and consequently to a smaller increase in the concentration of the active CAMP/ CRP complex. If this explanation is correct, overproduction of CRP in combination with CAMP addition should result in relief of catabolite repression. These experiments were without success, however, because the growth of cells containing pFCRP7 was severely inhibited by the addition of cAMP. This was also the case for cells that contained other crp-encoding plasmids (data not shown). At the maximal CAMP concentration that still allowed growth on glucose 6-phosphate (approx. $100 \mu \mathrm{M}$ ), we observed a small increase (30\%) in $\beta$-galactosidase activity. 
Because these experiments did not answer the question posed above, we measured repression in a $\mathrm{Cya}^{-} \mathrm{Crp}^{-}$ mutant that contained the plasmid pHA7G141D which constitutively expresses Crp* (Aiba et al., 1985). As cAMP is not synthesized and the amount of CRP* protein is constant, there should be no catabolite repression if catabolite repression is only regulated by CAMP and CRP. We found that glucose and lactose caused only $11 \%$ and $13 \%$ repression in this strain, respectively, while gluconate caused no repression at all (Table 1). From this we conclude that, although neither CAMP addition nor CRP overproduction lead to complete relief of glucose-, lactose- and gluconate-mediated repression, the combined decrease of both the CAMP and the CRP concentrations is the cause of catabolite repression by these carbohydrates. With glucose 6-phosphate, the results were more difficult to interpret, because the growth rate of the strain containing the plasmid pHA7G141D decreased strongly before the cells entered the mid-log phase. At lower cell densities, the $\beta$-galactosidase activity was only $31 \%$ lower than that in lactate-grown cells, indicating that catabolite repression by glucose 6-phosphate was also largely relieved in this strain. We conclude that the combined decrease in CAMP and CRP is responsible for the repression by glucose 6-phosphate.

The decrease in CAMP concentration caused by glucose 6-phosphate and gluconate is caused by decreased adenylate cyclase activity

The decrease in cAMP concentration caused by growth on gluconate or glucose 6-phosphate is probably the result of reduced adenylate cyclase activity (Gstrein-Reider and Schweiger, 1982; Epstein et al., 1975). Reduced adenylate cyclase activity could be caused either by a lowered amount or a lowered activity of adenylate cyclase. A plasmid containing a cya::lacZ protein fusion was used to distinguish between these two possibilities. Table 1 shows that the $\beta$-galactosidase activity of the fusion protein was approximately the same in cells grown on lactate, glucose 6-phosphate or gluconate; only in glucose-grown cells was the activity slightly lower, indicating that the regulation of the cAMP level in the cells is probably caused by a change in adenylate cyclase activity rather than in the amount of the enzyme.

\section{Discussion}

The involvement of the phosphorylation state of IIA ${ }^{\text {Glc }}$ of the PTS in PTS-mediated catabolite repression has been clearly established (for a review, see Postma et al., 1993). Although there is no mechanism known that could account for a change in the phosphorylation state of enzyme $\| A^{\text {Glc }}$ when non-PTS sugars are transported, it is possible that enzyme $\| A^{G l c}$ is also controlling catabolite repression by
non-PTS substrates. In a recent paper by Dumay et al. (1996), it was suggested that enzyme $I I A^{\text {Glc }}$ is indeed controlling the downregulation of the cAMP level in cells grown on glucose 6-phosphate. We have investigated the possible role of enzyme IIA ${ }^{\text {Glc }}$ by measuring catabolite repression by different carbon sources in a $\mathrm{Crr}^{-}$mutant (lacking enzyme $\| A^{G l c}$ ). It is concluded that enzyme IIA ${ }^{\text {Glc }}$ is not involved in repression by these compounds. This conclusion agrees with what is reported by Yang et al. (1979), who showed that glucose 6-phosphate and gluconate still cause catabolite repression in a mutant lacking enzyme I of the PTS, i.e. a condition in which enzyme $\| A^{\text {Glc }}$ is always in the dephosphorylated state.

A possible involvement of CAMP in catabolite repression by glucose 6-phosphate had already been suggested on the basis of a low cAMP level in glucose 6-phosphategrown cells (Epstein et al., 1975; Joseph et al., 1982) and by the absence of repression in the $E$. coli lacL8UV5 mutant (usually called lacUV5) (Table 1; Silverstone et al., 1970), a strain in which the lac promoter is independent of CAMP and CRP. Some reservations have to be made, however. The lacL8UV5 mutant contains two mutations in the lac promoter region. One of these mutations, the UV5 mutation, is a change in the -10 region of the promoter, which results in the optimal box (Reznikoff and Abelson, 1978). Apart from disturbing cAMP/CRP-dependent regulation (Rockwell and Gottesman, 1991), other regulatory processes could also be changed by this mutation. Because the lacL 8 mutant, which only has a mutation in the CRP-binding site of the promoter, is still repressed approx. fivefold by glucose 6-phosphate (Silverstone et al., 1970) and twofold by glucose (Wanner et al., 1978), it cannot be concluded that no factors other than CAMP and CRP are involved in catabolite repression by glucose 6-phosphate, gluconate and lactose only on the basis of the fact that repression by these carbohydrates is absent in the lacL8UV5 mutant. However, it is a strong indication that these factors are involved in the repression.

We have shown that the cAMP levels are low in cells grown on glucose 6-phosphate, gluconate and lactose compared to the level in lactate-grown cells (Table 2). These results confirm data reported by Epstein et al. (1975) and Joseph et al. (1982). The CRP levels in cells grown on these repressing carbon sources are also strongly reduced compared to the levels in cells grown on a nonrepressing carbon source (Table 2 ). In general, low concentrations of CAMP correlate with low levels of CRP, so a decrease in the CRP levels could contribute to catabolite repression by the different carbon sources. The amount of CAMP-CRP complex in cells grown on different carbon sources was calculated and plotted against the $\beta$-galactosidase activity (Fig. 1), assuming that the dissociation constant of the cAMP-CRP complex is $15 \mu \mathrm{M}$ (Cheng et al., 1993; Heyduk and Lee, 1989). A strong correlation 
is found between the concentration of the CAMP-CRP complex and the $\beta$-galactosidase activity. The combined decrease in CAMP and CRP in cells grown on repressing carbon sources offers an attractive explanation for the observed repression. The fact that repression by glucose, lactose and gluconate is relieved when the amount of CAMP/CRP is deregulated in a $\mathrm{Cya}^{-} \mathrm{Crp}^{-}$double mutant in which a crp* gene is constitutively expressed from a plasmid (Table 1) provides additional evidence that catabolite repression is only mediated by cAMP/CRP. Glucose 6 -phosphate decreased the $\beta$-galactosidase expression in this strain by only $31 \%$ at low cell densities. This decrease may be caused by CAMP/CRP-independent catabolite repression, but probably results from the fact that glucose 6-phosphate is toxic to this strain. At higher cell densities, the $\beta$-galactosidase activity decreased by more than $50 \%$, but the growth rate also decreased strongly, possibly due to the formation of methyl glyoxal (Ackerman et al., 1974; Kadner et al., 1992).

If catabolite repression is only cAMP/CRP dependent, it is expected that addition of extracellular CAMP or overexpression of CRP relieves catabolite repression. With glucose and gluconate, repression was relieved to a large extent, as had been shown previously for glucose (Ishizuka et al., 1993). In the case of lactose and glucose 6-phosphate, we found, to our surprise, that neither overproduction of CRP nor addition of cAMP could overcome catabolite repression. Similarly, raising the CAMP level by introducing a plasmid containing the adenylate cyclase gene behind an inducible promoter only had a small effect on glucose 6-phosphate repression. In the literature, different effects of cAMP addition on glucose 6-phosphate repression have been described, ranging from a nearly complete relief of repression (Perlman et al., 1969; Yang et al., 1979) to a mild increase in $\beta$-galactosidase activity without a strong effect on the repression (Goldenbaum and Dobrogosz, 1968), which is similar to the result we have obtained (Table 1). It is possible that the concentration of extracellular cAMP necessary to overcome repression by glucose 6 -phosphate is strain dependent, as is the case with glucose repression (Perlman et al., 1969). However, the growth of the (wild-type) strain MG1655 used in our studies, was severely inhibited by cAMP concentrations higher than $2.5 \mathrm{mM}$. Thus, we were not able to relieve the repression by adding more cAMP.

It may seem paradoxical that most results suggest that catabolite repression by glucose 6-phosphate, gluconate and lactose is CAMP/CRP dependent, but that we were unable to relieve the repression in a wild-type strain. We believe that the combination of low CAMP and low CRP levels in cells grown on lactose and glucose 6-phosphate can explain this apparent paradox. It should be noted that during growth on glucose 6-phosphate and lactose, the CRP levels are significantly lower than those in glucose-grown cells. When the CRP level is lower, the absolute effect of an increase in the intracellular concentration of CAMP on the concentration of the CAMP-CRP complex will be smaller. Moreover, addition of cAMP may lower the CRP level even further, because the crp promoter is negatively regulated by the cAMP-CRP complex when the levels of this complex are low (Hanamura and Aiba, 1992; Isizuka et al., 1994). If CRP is overproduced, on the other hand, the cAMP levels, which are already very low in cells grown on glucose 6-phosphate or lactose, may be too low to lead to an increase in the concentration of the complex and relieve repression. Furthermore, the CAMP level is probably further reduced by the increase in the CRP level, because both cya transcription and adenylate cyclase activity are negatively regulated by the cAMP-CRP complex (Aiba, 1985; Botsford and Harman, 1992). If this explanation is correct, repression cannot be relieved by either adding CAMP or overproducing CRP when the levels of both CAMP and CRP are low. The CRP level in cells grown on glucose is strain dependent (Ishizuka et al., 1993). If the same is true with glucose 6-phosphate, the effect of adding CAMP in strains with a low CRP level will be smaller than in strains with a higher CRP level. This could explain why some groups have found that CAMP addition relieves catabolite repression by glucose 6-phosphate (Perlman et al., 1969; Yang et al., 1979), while we and others only found a small effect on the repression (Table 1; Goldenbaum and Dobrogosz, 1968).

How can glucose 6-phosphate, lactose and gluconate lower the CAMP and CRP levels? The most likely explanation for the decrease in the cAMP level is a decrease in the cAMP synthesis rate. Increased cAMP excretion cannot be the cause, because extracellular and intracellular levels of cAMP are lowered to the same extent by these carbon sources (B. M. Hogema, unpublished; Epstein et al., 1975), and cAMP breakdown by phosphodiesterase is unlikely to play a role in catabolite repression (Table 1; Botsford, 1981). Using a cya::lacZ fusion protein with a functional cya gene, we demonstrated that the carbon source does not have a strong influence on the amount of fusion protein produced (Table 1). We conclude that it is not the amount but the activity of adenylate cyclase that is regulated by glucose 6-phosphate and gluconate. Other experiments showed that the activity of adenylate cyclase in washed cell suspensions in the absence of a carbon source is inversely related to the intracellular cAMP concentration (Joseph et al., 1982). In this case, the adenylate cyclase activity probably reflects the amount of enzyme rather than the activity during growth. The high adenylate cyclase activity in glucose 6-phosphate-grown cells therefore suggests that the amount of adenylate cyclase is high in cells grown on glucose 6-phosphate or glucose, and is much lower in cells grown on a non-repressing carbon 
source. This result was also found with a Salmonella typhimurium cya::lacZ transcriptional fusion (Fandl et al., 1990). These facts together show that the regulation of adenylate cyclase by different carbon sources is post-translational. The mechanism of this post-translational regulation is still not elucidated. Control of adenylate cyclase activity is probably exerted via the uptake systems of different (PTS and non-PTS) carbon sources. This control should be independent of subsequent metabolism, because non-metabolizable analogues of lactose, glucose and galactose are able to decrease the cAMP accumulation in starving cells to about the same extent as the metabolizable sugars, provided that the uptake systems are induced (Gstrein-Reider and Schweiger, 1982). Recently it was shown that the total amount of cAMP in cultures grown on glucose 6-phosphate is indeed dependent on the transport capacity. A correlation between cAMP levels and the doubling time was shown when the amount of UhpT protein was modulated using an IPTG-inducible uhpT expression vector (Dumay et al., 1996). Using a similar expression vector, it was found that the activity of $\beta$-galactosidase was also high in cells grown slowly on glucose 6-phosphate (B. M. Hogema, unpublished). The non-metabolizable glucose 6-phosphate analogue, 2-deoxyglucose 6-phosphate, also lowered the cAMP level in cells grown on pyruvate, showing that also in the case of glucose 6-phosphate, metabolism is not required for the regulation of adenylate cyclase activity (Dumay et al., 1996). In addition, 2-deoxyglucose
6 -phosphate causes repression of $\beta$-galactosidase (Kanazawa and Anraku, 1977), and glucose 6-phosphate causes catabolite repression in a mutant that is unable to metabolize glucose 6-phosphate (J. C. Arents, unpublished; Kanazawa and Anraku, 1977), also showing that metabolism is not involved in catabolite repression.

The carbon source-dependent regulation of the CRP level is not fully understood. It has been shown that the decrease in CRP level during growth on glucose is caused by the dual regulation of the crp gene, which is regulated both positively and negatively by the CAMP-CRP complex (Ishizuka et al., 1994). The concentration of the complex needed for stimulation of the transcription is higher than the concentration needed for inhibition (Hanamura and Aiba, 1992). It was suggested that the CRP decrease is triggered by a decrease in CAMP, leading to a lowered concentration of the CAMP-CRP complex, resulting in less stimulation of CRP transcription (Ishizuka et al., 1994). It is possible that a similar mechanism causes the decrease of CRP in cells grown on gluconate, lactose and glucose 6-phosphate. The mechanism of the decrease in CRP concentration will be the subject of further studies.

\section{Experimental procedures}

\section{Bacterial strains and plasmids}

The E. coli strains and plasmids used in this study are listed in Table 4.

Table 4. List of E. coli strains and plasmids used in this study.

\begin{tabular}{|c|c|c|}
\hline Strain/Plasmid & Relevant genotype/phenotype & Source/Reference \\
\hline \multicolumn{3}{|l|}{ Strain } \\
\hline ATCC8739 & $c p d A$ & ATCC \\
\hline CA8050 & lacL8UV5 thi-1 & P. R. Jensen \\
\hline CAG12080 & zah-281::Tn 10 & Singer et al. (1989) \\
\hline CAG18456 & cysG zhe-3084::Tn 10 & Singer et al. (1989) \\
\hline CAG18468 & nupC510::Tn 10 & Singer et al. (1989) \\
\hline DW2 & $r p s L \Delta($ melB $) \Delta(l a c Z Y)$ & G. Leblanc \\
\hline IT1106 & $\Delta($ cya-854::Cm) crp*B1 & T. Inada \\
\hline LM1 & crr-1 thi-1 his-1 argG6 metB galT rpsL manXYZ manl nagE & J. Lengeler \\
\hline MG1655 & Wild type & B. Bachmann \\
\hline PP47 & crp-1 & Ishizuka et al. (1994) \\
\hline PPA237 & crr-1 nupC510::Tn10 thi-1 his-1 argG6 metB galT rpsL manXYZ manl nagE & LM1 $\times$ P1.CAG18468 \\
\hline PPA418 & $\Delta($ cyaA1400::Km) & MG1655×P1.SP850 \\
\hline PPA484 & crr-1 nupC510::Tn 10 & MG1655×P1.PPA237 \\
\hline PPA522 & $r p s L \Delta($ melB $) \Delta(l a c Z Y)$ zah-281::Tn10 & DW2×P1.CAG12080 \\
\hline PPA523 & $\Delta($ lacZY $)$ zah-281::Tn 10 & MG1655×P1.PPA522 \\
\hline PPA529 & crp-1 zhe-3084::Tn 10 & PP47×P1.CAG18456 \\
\hline PPA530 & $\Delta($ cyaA1400::Km) crp-1 zhe-3084::Tn 10 & PPA418×P1.PPA529 \\
\hline PPA549 & lacL8UV5 & PPA523 × P1.CA8050 \\
\hline SP850 & $\Delta($ cyaA1400::Km) & Shah and Peterkofsky (1991) \\
\hline \multicolumn{3}{|l|}{ Plasmid } \\
\hline plT296 & cya-lacZ fusion derived from $\mathrm{pMC1403,} \mathrm{Ap}^{\mathrm{R}}$ & T. Indada \\
\hline pFCRP7 & Constitutive low level crp plasmid & Ishizuka et al. (1993) \\
\hline pHA7G141D & Expresses $c r p *$ constitutively & Aiba et al. (1985) \\
\hline pBCP540 & Expression vector containing adenylate cyclase & This work \\
\hline
\end{tabular}

$\mathrm{Cm}$, chloramphenicol-resistance gene; $\mathrm{Km}$, kanamycin-resistance gene; $\mathrm{Ap}^{\mathrm{R}}$, ampicillin resistant; $\mathrm{P} 1$, phage $\mathrm{P} 1$. 


\section{Media and growth conditions}

Cells were grown in $50 \mathrm{ml}$ Erlenmeyer flasks at $37^{\circ} \mathrm{C}$ on a rotary shaker. Minimal medium A ( $\mathrm{pH} 7)$ contained $1 \mathrm{~g}\left(\mathrm{NH}_{4}\right)_{2} \mathrm{SO}_{4}$, $10.5 \mathrm{~g} \mathrm{~K}_{2} \mathrm{HPO}_{4}, 4.5 \mathrm{~g} \mathrm{KH}_{2} \mathrm{PO}_{4}$ and $0.1 \mathrm{~g} \mathrm{MgSO}_{4} \cdot 7 \mathrm{H}_{2} \mathrm{O}$ per litre of demineralized water. Cells were first pre-grown in rich medium (A medium containing 1\% tryptone) for $8-16 \mathrm{~h}$ and then diluted $1: 80$ in $10 \mathrm{ml}$ of $A$ medium containing $0.4 \%$ $(\mathrm{w} / \mathrm{v}) \mathrm{D}, \mathrm{L}-\mathrm{lactate}$ as the carbon source. After overnight growth, the cells were still in the logarithmic phase and were diluted to the desired optical density (monitored at $600 \mathrm{~nm}$ ) in A medium containing $0.4 \%$ lactate and $0.2 \%$ of the other indicated carbon sources. The optical density to which cells were diluted was usually 0.025 if lactate was the sole carbon source, and 0.005 when the cells were grown on a carbon source that supported fast growth. When appropriate, $20 \mu \mathrm{g} \mathrm{ml}^{-1}$ of necessary amino acids were added. When cells contained plasmids, ampicillin was added at $100 \mu \mathrm{g} \mathrm{ml}^{-1}$.

\section{Construction of $p B C P 540$}

To clone the $E$. coli adenylate cyclase gene behind the L-arabinose-inducible promoter from pBAD18 (Guzman et al., 1995), the cya gene was first cloned at the optimal distance from a ribosome-binding site (RBS) in plasmid pT7.7 (Tabor and Richardson, 1985). The $4.4 \mathrm{~kb}$ Ndel-Sall fragment from pPR100 (Amin and Peterkofsky, 1992) containing the cya gene, was inserted in pT7.7 digested with Ndel and Sall, resulting in pBCP530. pBCP530 was digested with Xbal, treated with Klenow fragment of DNA polymerase I, digested with Sall, and the $4.4 \mathrm{~kb} \mathrm{Xbal-Sall} \mathrm{fragment} \mathrm{containing} \mathrm{the}$ cya gene (with RBS) was cloned behind the ara promoter of pBAD18 (provided by M. Ehrmann; Guzman et al., 1995) that had been digested with Smal and Sall, resulting in pBCP540.

\section{Beta-galactosidase assay}

Beta-galactosidase activity was determined in permeabilized cells using the improved method of Giacomini et al. (1992). Cells were grown as described above with $400 \mu \mathrm{M}$ IPTG (maximal induction). As the optical density after dilution increased more than 20 -fold (see Media and growth conditions), this ensured at least four doublings. The $\beta$-galactosidase activity was constant at $\mathrm{OD}_{600}$ levels of between 0.1 and 0.6. During growth at least three samples were taken and analysed while the cells were in this growth phase. The average value of at least two independent experiments was taken. The standard error of the mean (SEM) was always less than $10 \%$. When cells were grown on lactate as the sole carbon source, the $\beta$-galactosidase activity was slightly dependent on the growth phase. A maximum level was reached in the early log phase $\left(O D_{600} \approx 0.25\right)$. We therefore analysed samples while the cells were at $O_{600}$ levels of between 0.2 and 0.3 when the cells were grown on lactate as the sole carbon source.

\section{cAMP measurement}

To determine the intracellular cAMP levels as accurately as possible, we compared several methods of harvesting the cells, namely centrifugation, filtration and quenching in cold $\left(-40^{\circ} \mathrm{C}\right)$ methanol. We used perchloric acid and boiling to prepare cell extracts after harvesting. The most reliable method was a combination of filtration and boiling. Cells were grown to an $\mathrm{OD}_{600}$ of 0.5 in A medium containing the indicated carbon source. Three $\mathrm{ml}$ of culture was then filtered through a Whatman GF/F glass fibre filter, and immediately washed with $3 \mathrm{ml}$ of ice cold A medium. The cells were extracted by placing the filter in $2.5 \mathrm{ml}$ of $0.2 \mathrm{M}$ hot formic acid in a glass vial which was pre-heated for $1 \mathrm{~min}$ in a boiling-water bath. The entire filtration procedure was completed in less than $15 \mathrm{~s}$. The cells were boiled for $8 \mathrm{~min}$. Before use, the glass vials were boiled with $0.2 \mathrm{M}$ formic acid for $10 \mathrm{~min}$ and then dried; this lowered the background in cells unable to synthesize cAMP (IT1106) from an apparent intracellular cAMP concentration of $1 \mu \mathrm{M}$ to less than $0.1 \mu \mathrm{M}$. After boiling the cells, the extract was centrifuged for $5 \mathrm{~min}$ in an Eppendorf microcentrifuge to remove cell debris and glass particles. Next, $1.5 \mathrm{ml}$ of the supernatant was freeze-dried, dissolved in $95 \mu \mathrm{l}$ of water, and the $\mathrm{pH}$ was adjusted to 7 with $1 \mathrm{M}$ $\mathrm{NaOH}$. After addition of $2.5 \mu \mathrm{l}$ of $2 \mathrm{M}$ potassium phosphate buffer $\mathrm{pH} 7$, the samples were analysed by means of a radioactive immunoassay (Tovey et al., 1974; Gilman, 1970). All samples were analysed three or four times; different amounts of sample and an internal standard were used. Average values of at least three independent experiments were calculated. The following conversion factors were used to calculate the intracellular cAMP concentrations: an $O_{600}$ of 1 corresponds to $350 \mathrm{\mu g} \mathrm{ml}^{-1}$ dry weight, and $1 \mathrm{mg}$ of dry weight corresponds to an internal volume of $2.48 \mu \mathrm{l}$ (Winkler and Wilson, 1966; Zwaig et al., 1970). For determination of the extracellular CAMP concentration, the culture was centrifuged for $2 \mathrm{~min}$ and the supernatant was analysed as obtained, after two- to fivefold dilution in $50 \mathrm{mM}$ potassium phosphate buffer.

\section{Determination of CRP}

Western blotting was performed as described (Ishizuka et al., 1993). Culture samples equivalent to $1 \mathrm{ml}$ with an $\mathrm{OD}_{600}$ of 0.5 were centrifuged and the pellets were resuspended in $500 \mu \mathrm{l}$ of loading buffer and heated at $95^{\circ} \mathrm{C}$ for $10 \mathrm{~min}$. Next, $10 \mu \mathrm{l}$ of this solution was loaded onto SDS-polyacrylamide gels, and, after blotting onto nitrocellulose, the blots were treated as described previously (Ishizuka et al., 1993), using polyclonal anti-CRP antibody and a horseradish peroxidase-conjugated secondary antibody. The absolute amount of CRP in cell-free extracts was determined by comparing the extracts with purified CRP, which was purified by the procedure of Eilen et al. (1978). For detection, the Amersham ECL kit was used according to the method specified by the manufacturer. Because the signal was dependent on the presence of cellfree extract, the values were corrected using a calibration curve made with purified CRP and different amounts of cellfree extract from a $\mathrm{Crp}^{-}$mutant (PP47). The films were scanned with a Sharp JX-330 transmission scanner and the bands were quantified using Pharmacia Image System 1D software.

\section{Acknowledgements}

The authors would like to thank Hideaki Tagami for helpful suggestions, Conchita Schulkes for help with the cAMP 
assay and for providing the cAMP-binding protein, Johan van der Vlag for critically reading the manuscript, and all colleagues who have provided strains and plasmids. This work was supported by a grant from the Nissan/NWO Fellowship Programme. B.M.H. is supported by the Netherlands Organization for Scientific Research (NWO), under the auspices of the Netherlands Foundation for Chemical Research (SON).

\section{References}

Ackerman, R.S., Cozzarelli, N.R., and Epstein, W. (1974) Accumulation of toxic concentrations of methylglyoxal by wild-type Escherichia coli K-12. J Bacteriol 119: 357362.

Aiba, H. (1985) Transcription of the Escherichia coli adenylate cyclase gene is negatively regulated by CAMP-CAMP receptor protein. J Biol Chem 260: 3063-3070.

Aiba, H., Nakamura, T., Mitani, H., and Mori, H. (1985) Mutations that alter the allosteric nature of cAMP receptor protein of Escherichia coli. EMBO J 4: 3329-3332.

Amin, N., and Peterkofsky, A. (1992) Requirement for gly 60 of Escherichia coli adenylate cyclase for ATP binding and catalytic activity. Biochem Biophys Res Commun 182: 1218-1225.

Botsford, J.L. (1981) CAMP and regulation of carbohydrate metabolism. In Trends in the Biology of Fermentations for Fuels and Chemicals. Hollaender, A., and Rabson, R. (eds). New York: Plenum Publishing Corporation, pp. 315334.

Botsford, J.L., and Harman, J.G. (1992) Cyclic AMP in prokaryotes. Microbiol Rev 56: 100-122.

Cheng, X., Gonzales, M.L., and Lee, J.C. (1993) Energetics of intersubunit and intrasubunit interactions of Escherichia coli adenosine $3^{\prime}, 5^{\prime}$-phosphate receptor protein. Biochemistry 32: 8130-8139.

Dumay, V., Danchin, A., and Crasnier, M. (1996) Regulation of Escherichia coli adenylate cyclase activity during hexose phosphate transport. Microbiology 142: 575-583.

Eilen, E., Pampeno, C., and Krakow, J.S. (1978) Production and properties of the $\alpha$ core derived from the cyclic adenosine monophosphate receptor protein of Escherichia coli. Biochemistry 17: 2469-2473.

Epstein, W., Rothman-Denes, L.B., and Hesse, J. (1975) Adenosine 3', 5'-cyclic monophosphate as mediator of catabolite repression in Escherichia coli. Proc Natl Acad Sci USA 72: 2300-2304.

Fandl, J.P., Thorner, L.K., and Artz, S.W. (1990) Mutations that affect transcription and cyclic AMP-CRP regulation of the adenylate cyclase gene (cya) of Salmonella typhimurium. Genetics 125: 719-727.

Giacomini, A., Corich, V., Ollero, F.J., Squartini, A., and Nuti, M.P. (1992) Experimental conditions may affect reproducibility of the $\beta$-galactosidase assay. FEMS Microbiol Lett 100: 87-90.

Gilman, A.G. (1970) A protein binding assay for adenosine $3^{\prime}: 5^{\prime}$-cyclic monophosphate. Proc Natl Acad Sci USA 67: 305-312.

Goldenbaum, P.E., and Dobrogosz, W.J. (1968) The effect of cyclic $3^{\prime}, 5^{\prime}$-AMP on catabolite repression of $\beta$-galactosidase synthesis in Escherichia coli. Biochem Biophys Res Commun 33: 828-833.
Gstrein-Reider, E., and Schweiger, M. (1982) Regulation of adenylate cyclase in E. coli. EMBO J 1: 333-337.

Guzman, L.M., Belin, D., Carson, M.J., and Beckwith, J. (1995) Tight regulation, modulation and high level expression by vectors containing the arabinose $\mathrm{P}_{\mathrm{BAD}}$ promoter. $J$ Bacteriol 177: 4121-4130.

Hanamura, A., and Aiba, H. (1992) A new aspect of transcriptional control of the Escherichia coli crp gene: positive autoregulation. Mol Microbiol 6: 2489-2497.

Heyduk, T., and Lee, J.C. (1989) Escherichia coli cAMP receptor protein: evidence for three protein conformational states with different promoter binding affinities. Biochemistry 28: 6914-6924.

Inada, T, Kimata, K., and Aiba, H. (1996) Mechanism responsible for glucose-lactose diauxie in Escherichia coli: challenge to the cAMP model. Genes Cells 1: 293-301.

Ishizuka, H., Hanamura, A., Kunimura, T., and Aiba, H. (1993) A lowered concentration of cAMP receptor protein caused by glucose is an important determinant for catabolite repression in Escherichia coli. Mol Microbiol 10: 341-350.

Ishizuka, H., Hanamura, A, Inada, T., and Aiba, H. (1994) Mechanism of the down-regulation of cAMP receptor protein by glucose in Escherichia coli: role of autoregulation of the crp gene. EMBO J 13: 3077-3082.

Jacob, F., and Monod, J. (1961) Genetic regulatory mechanisms in the synthesis of proteins. $J \mathrm{Mol} \mathrm{Biol} 3$ : 318-356.

Joseph, E., Bernsley, C., Guiso, N., and Ullmann, A. (1982) Multiple regulation of the activity of adenylate cyclase in Escherichia coli. Mol Gen Genet 185: 262-268.

Kadner, R.J., Murphy, G.P., and Stephens, C.M. (1992) Two mechanisms for growth inhibition by elevated transport of sugar phosphates in Escherichia coli. J Gen Microbiol 138: 2007-2014.

Kanazawa, H., and Anraku, Y. (1977) Transient repression of $\beta$-galactosidase synthesis by glucose 6 -phosphate in a mutant of Escherichia coli lacking enzyme II specific for glucose in the phosphoenolpyruvate-sugar phosphotransferase system. J Biochem 83: 1137-1343.

Kolb, A., Busby, S., Buc, H., Garges, S., and Adhya, S. (1993) Transcriptional regulation by CAMP and its receptor protein. Annu Rev Biochem 62: 749-795.

Magasanik, B. (1961) Catabolite repression. Cold Spring Harbor Symp Quant Biol 26: 249-256.

Magasanik, B. (1970) Glucose effects: Inducer exclusion and repression. In The Lactose Operon. Beckwith, J.R., and Zipser, D. (eds.), Cold Spring Harbor, New York: Cold Spring Harbor Laboratory Press, pp. 189-220.

Magasanik, B., and Neidhardt, F.C. (1987) Regulation of carbon and nitrogen utilization. In Escherichia coli and Salmonella typhimurium: Cellular and Molecular Biology. 1st edn. Neidhardt, F.C., Ingraham, J.L., Low, K.B., Magasanik, B., Schaechter, M., and Umbarger, H.E. (eds). Washington, DC: American Society for Microbiology, pp. 1318-1325.

Monod, J. (1942) Recherches sur la Croissance des Cultures Bactériennes. 2nd edn. Paris: Hermann.

Mori, K., and Aiba, H. (1985) Evidence for negative control of cya transcription by cAMP and CAMP receptor protein in intact Escherichia coli cells. J Biol Chem 260: 1483814843.

Okinaka, R.T., and Dobrogosz, W.J. (1966) Enhanced 
catabolite repression in Escherichia coli by growth on combined substrates. J Bacteriol 92: 526-527.

Perlman, R.L., De Crombrugghe, B., and Pastan, I. (1969) Cyclic AMP regulates catabolite and transient repression in E. coli. Nature 223: 810-812.

Postma, P.W., and Lengeler, J.W. (1985) Phosphoenolpyruvate:carbohydrate phosphotransferase system of bacteria. Microbiol Rev 49: 232-269.

Postma, P.W., Lengeler, J.W., and Jacobson, G.R. (1993) Phosphoenolpyruvate:carbohydrate phosphotransferase systems of bacteria. Microbiol Rev 57: 543-594.

Reznikoff, W.S., and Abelson, J.N. (1978) The lac promoter. In The Operon. Miller, J.H., and Reznikoff, W.S. (eds). Cold Spring Harbor, New York: Cold Spring Harbor Laboratory Press, pp. 221-244.

Rockwell, P., and Gottesman, M.E. (1991) An Escherichia coli rpo $B$ mutation that inhibits transcription of catabolitesensitive operons. $J$ Mol Biol 222: 189-196.

Saier, M.H., Ramseier, T.M., and Reizer, J. (1996) Regulation of carbon utilization. In Escherichia coli and Salmonella: Cellular and Molecular Biology. 2nd edn. Neidhardt, F., Curtiss, R, Ingraham, J.L., Lin, E.C.C., Low, K.B., Magasanik, B., Reznikoff, W.S., Riley, M., Schaechter, M., and Umbarger, H.E. (eds). Washington, DC: American Society for Microbiology, pp. 1325-1343.

Shah, S., and Peterkofsky, A. (1991) Characterization and generation of Escherichia coli adenylate cyclase mutants. J Bacteriol 173: 3238-3242.

Silverstone, A.E., Arditti, R.R., and Magasanik, B. (1970) catabolite-insensitive revertants of lac-promoter mutants. Proc Natl Acad Sci USA 66: 773-779.

Singer, M., Baker, T.A., Schnitzler, G., Deischel, S.M., Goel,
M., Dove, W., Jaacks, K.J., Grossman, A.D., Erickson, J.W., and Gross, C.A. (1989) A collection of strains containing genetically linked alternating antibiotic resistance elements for genetic mapping of Escherichia coli. Microbiol Rev 53: 1-24.

Tabor, S., and Richardson, C.C. (1985) A bacteriophage T7 RNA polymerase/promoter system for controlled expression of specific genes. Proc Natl Acad Sci USA 82: 10741078.

Tagami, H., Inada, T., Kunimura, T., and Aiba, H. (1995) Glucose lowers CRP* levels resulting in repression of the lac operon in cells lacking cAMP. Mol Microbiol 17: 251258.

Tovey, K.C., Oldham, K.G., and Whelan, J.A.M. (1974) A simple direct assay for cyclic AMP in plasma and other biological samples using an improved competition protein binding technique. Clin Chim Acta 56: 221-234.

Ullmann, A., and Danchin, A. (1983) Role of cyclic AMP in bacteria. Adv Cycl Nucl Res 15: 1-53.

Wanner, B.L., Kodeira, R., and Neidhardt, F.C. (1978) Regulation of lac operon expression: reappraisal of the theory of catabolite repression. J Bacteriol 136: 947-954.

Winkler, H.H., and Wilson, T.H. (1966) The role of energy coupling in the transport of $\beta$-galactosides by Escherichia coli. J Biol Chem 241: 2200-2210.

Yang, J.K., Bloom, R.W., and Epstein, W. (1979) Catabolite and transient repression in Escherichia coli do not require enzyme I of the phosphotransferase system. J Bacteriol 38: 275-279.

Zwaig, N., Kostler, W.S., and Lin, E.C.C. (1970) Glycerol kinase, the pacemaker for the dissimilation of glycerol in Escherichia coli. J Bacteriol 102: 753-759. 